Journal of Economics and Behavioral Studies

Vol. 6, No. 9, pp. 700-708, September 2014 (ISSN: 2220-6140)

\title{
Creating Hospitals' Core Competencies with Lean Healthcare Strategies Entering the ASEAN Economic Community
}

\author{
Pareeyawadee Ponanake*, Sunpasit Limnararat, Manat Pithuncharurnlap, Woranat Sangmanee, \\ King Mongkut's Institute of Technology, Bangkok, Thailand \\ *pareeyawadee@gmail.com
}

\begin{abstract}
This study aimed to evaluate the structural equation modeling of the influences between Lean healthcare strategies, internal quality management and hospitals' core competencies as medical care centers entering the ASEAN Economic Community. The populations and sample groups in this study included $384 \mathrm{HA}$ officers. The research was conducted from December 2012 to August 2013, and the research method involved purposive sampling through questionnaires. A statistical data analysis was performed using Structural Equation Modeling analysis. This study found that 1) Lean healthcare strategies indirectly influenced hospitals' core competencies as medical centers entering the ASEAN Economic Community through internal quality management at the 0.01 significance level, 2) Lean healthcare strategies directly influenced hospitals' core competencies as medical centers entering the ASEAN Economic Community at the 0.01 significance level; 3 ) Lean healthcare strategies directly influenced internal quality management at the 0.01 significance level; and 4) internal quality management directly influenced hospitals' core competencies as medical centers entering the ASEAN Economic Community at the 0.01 significance level.
\end{abstract}

Keywords: Lean Healthcare, Internal Quality Management, Core Competency, AEC, Medical Care Center

\section{Introduction}

The service industry has expanded rapidly in recent years, and several ideas and methodologies have been applied within enterprises and industries. The most famous method is the Lean method, which has been shown to improve service efficiency by 55\%. The most popular industry in which the Lean method has been applied is the health industry (Radnor, 2010). Lean refers to the process of reducing waste and increasing productivity through analysis and continuous improvement (Womack \& Jones, 1996). Lean healthcare has been applied broadly (Brandao de Souza, 2009). Many years ago, various hospitals applied Lean Healthcare (Radnor, 2010) to encourage motivation toward service improvement and delivery (Robinson et al., 2012). Quality management was developed in terms of meaning and ideas (Sousa \& Voss, 2002) through traditional quality management methodologies that addressed the improvement of the efficiency of organizations (Dean and Bowen, 1994). However, the outstanding factors of quality management include the principal, the practices and techniques used by the principal, general guidelines and practices to support these techniques of quality management ( $\mathrm{Zu}$ et al., 2008). Quality management sets the practices of organizations, such as a customer-centered focus, continuous improvement and administrative improvement, and teamwork (Bowen \& Youngdahl, 1998; Prajogo \& McDermott, 2005; Sousa \& Voss, 2002).

All industrial agencies, including the healthcare industry, have developed strategies to respond to environmental factors and competitive challenges. The important problems faced by the healthcare industry include spiraling costs and medical errors. Eliminating medical errors leads to significant cost reductions (Grout \& Toussaint, 2010). The idea of process failure reduction could be succeeded by Lean's methodology to reduce error and waste processes (Grout \& Toussaint, 2010). The flow model measures waiting times, which is an important measure reflecting accessibility in the Lean principles of specifying value, value streams and applying a pull strategy. Waiting times can be measured by the amount of time a patient group waits for a visit or a treatment. The number of patients waiting can also be measured by the demand for care or treatment registered. In entering the AEC, Thailand has an advantage in healthcare competition compared with neighboring countries, as Thailand has emphasized targeting specific markets, the high quality of healthcare and the biggest hospitals in Asia, which include Bangkok Hospital and Bumrungrad Hospital. These hospitals were certified by the ISO 9002 and possess JCI accreditation (Enderwick \& Nagar, 2011). 
This study aimed to evaluate the structural equation modeling of the influences between Lean healthcare strategies, internal quality management and hospitals' core competencies as medical care centers entering the ASEAN Economic Community.

\section{Literature Review}

The Lean system originated from the Toyota production system (TPS) of the Toyota Motor Corporation, which modified the traditional method of mass production and batched principles, leading to operational efficiency, quality, speed and better margins (Holweg, 2007). Even though the Lean idea was not complex, the process was not easily implemented. The Lean production method was able to continuously improve and eliminate non-value added steps or waste (or "Muda" in Japanese). Taiichi Ohno defined the basic types of waste in the production environment and applied them to the healthcare context.

Table 1: Seven forms of waste in the healthcare business

\begin{tabular}{ll}
\hline Wastes & Healthcare Business \\
\hline 1. Transportation & - HA officers waste time walking and picking up documents from the ward. \\
& - Medical equipment is kept in the center of the facility instead of keeping \\
& appropriate equipment in each division. \\
2. Inventory & - Stocks in storerooms are in excess without being used. \\
& - Patients' waiting time is too long when being discharged. \\
& - Long waiting lists for meeting with doctors. \\
3. Motion & - Unnecessary movement from HA officers to find documents. \\
& - No standard equipment in examination rooms. \\
4. Waiting / Delay & - Waiting for staff results, prescriptions and drugs. \\
& - Waiting for doctors' examinations. \\
5.Overproduction & - Unnecessary requests for pathology tests. \\
& - Scheduling appointments "just in case." \\
6.Over-Processing & - Duplication of information \\
& - Too many interviews with patients. \\
7. Defect & - Readmission due to errors in examinations. \\
& - Double tests due to a lack of preparation of correct data. \\
\hline
\end{tabular}

Radnor et al. (2012) explained that waste concentration was Lean's only limitation or Muda, which related to the idea of "Mura," concerning unevenness and the problem of stable demand that results from little process variation and highly efficient processes, including standardized processes. In addition, Muda is related to excessive strain (or "Muri") and the problem of ensuring good working environments, safety and accident protection. Therefore, we can define the above factors of Lean's idea as follows: "Lean is a management practice based on the philosophy of the standard of continuous improvement process emphasizing patients' value increase, the reduction of unnecessary activities (Muda), process variation (Mura) and poor working conditions (Muri)." Lean's activities were separated into three different points of view: assessment, improvement and performance processes. Assessment includes a review of process efficiency in organizations in terms of waste, flow and value added capacity, such as waste walks, multiple steps, value stream mapping, improvement support activities and procedures such as Kaizen blitz or Kaikaku events taking more than 3-5 days, staff evaluation, development and new process design with housekeeping tools such as 5S. 5S is comprised of sorting, setting in order, sweeping, standardizing and sustaining, and process control and visual control, which are tools of data flow, standard operating procedures (SOPs) and performance data. To evaluate Lean's impact overall, it is necessary to clearly explain the following definitions:

- The possibility of value and waste from customers' view until waste activities are identified.

- The identification and advantage measurement to reduce the non-value added activities, such as cost reduction and an increase in competition.

- Independent resources supporting the growing business.

Lean Service: Lean Service (Bowen \& Youngdahl, 1998) is comprised of: 
- Reduction in performance trade-offs consisting of the operational goals focused on internal efficiency and customer flexibility.

- Flow service and JIT pull consisting of customer flow and JIT Service.

- Value-chain orientation consisting of value analysis to eliminate the non-value added activities of customers.

- Increased focus on customers consisting of customer involvement in the design of the service packages, employee training in customer service skills and behaviors, and customer training in how to contribute to quality services.

- Employee empowerment consisting of human capital in employees such as skills, teambuilding, and participation.

Lean Healthcare: Lean can be applied to the central administration and local administration of the healthcare industry (Radnor, 2010). To apply Lean in the healthcare industry, hospitals should reduce duplicate processes and unnecessary steps, such as keeping patients' data in many places, long waiting times and unnecessary waiting times (Radnor et al., 2012). As per the Lean Healthcare concept, the patient is the most important customer, so a hospital should meet customers' needs by maintaining quality standards so that patients can access services easily and conveniently. Therefore, the hospital should establish customer satisfaction from initial contact until the patient leaves the hospital. However, the hospital should focus on patient flow and patients' data flow, which should include designing a new package service in order to decrease waiting time in activities such as waiting for the doctor, waiting for blood to be drawn, etc. Moreover, the hospital should focus on interactions between hospital staff and patients, and the hospital should focus on the participation of customers, such as checking health programs, etc.

In first applying Lean in hospitals, there were conflicting points of view involving quality improvement and data and patient flow. The best way of ensuring quality patient treatment involves the following steps: The first step is to draw process maps then evaluate waste in processes by value stream mapping: VSM of documents identified the duration of procedures and the quantity and time of value added and non-value added activities. In each step, the process plan improves teamwork and processing steps to add value to patients' experience. Each step uses sources and times including the margins without value added. In the next step, teamwork should be used to identify the design objective of new mapping procedures to cut losses as much as possible, including losses due to waiting time in patient admission, exam results or patients' movements for admission (Dickson et al., 2009).

Internal Quality Management: Service differs from goods production because service quality involves an element of time as well as a degree of interaction between staff and customers. Accordingly, service quality (Russell \& Talor III, 2011) includes the following dimensions:

- Time and Timeliness: How long do the customers wait for service or was the service completed on time? In the case where delivered goods were returned, would the goods be delivered overnight?

- Completeness: Was the response to the customer's demand satisfactorily completed? Were the goods ordered via catalogue or purchase order delivered within a satisfactory timeframe?

- Courtesy: Were the customers treated appropriately by the company's representatives? Were the company's representatives polite and efficient when dealing with customers over the telephone?

- Consistency: Was daily service delivery prompt and on time? For example, was the newspaper delivered on time every day?

- Accessibility and Convenience: Was the service easy for customers to access and use? For example, when customers called in to place an order, was the call answered quickly?

- Accuracy: Was the service efficient and accurate every time? For example, was the bank account statement accurate every month?

- Responsiveness: How does the company address the unexpected problems that often occur in a service company? For example, can the operators answer questions about goods listed in the catalogue if the catalogue did not provide adequate details of the goods?

Competencies of Organizations: Daft (2010) mentioned the definition of Core Competence that is the something the organization does especially well when benchmark with their competitors. A core competence 
may be in the area of research and development, expert technological know-how, process efficiency, or customer service. Also Shuai et al. (2007) studied regarding core competency of organization influence on supply chain management; it comprised of operational processes, planning and monitoring services, and behavioral processes

\section{Methodology}

Material: The research tools used for data collection were questionnaires consisting of 4 parts. Part 1 included general questions about private hospitals in Thailand. Part 2 included questions about the Lean healthcare strategy concentrating on efficiency tradeoffs, service flow, value chain orientation, customer service orientation and training and employee empowerment. Part 3 included questions about internal quality management focusing on service efficiency, service processes and service outcomes. Part 4 included questions about the hospitals' core competencies as medical centers entering the AEC focusing on operational processes, planning and monitoring services and behavioral services.

Methods: The population and sample groups in this study included the HA officers of private Thai hospitals during the period between December 2012 and August 2013. The sample group totaled 384 persons. Questionnaires were used as the main method of data collection. The exogenous variable was the Lean healthcare strategy. The endogenous variables were internal quality management and the core competencies of private Thai hospitals as medical care centers. Research framework as shown in figure 1.

\section{Figure 1: Research Framework}

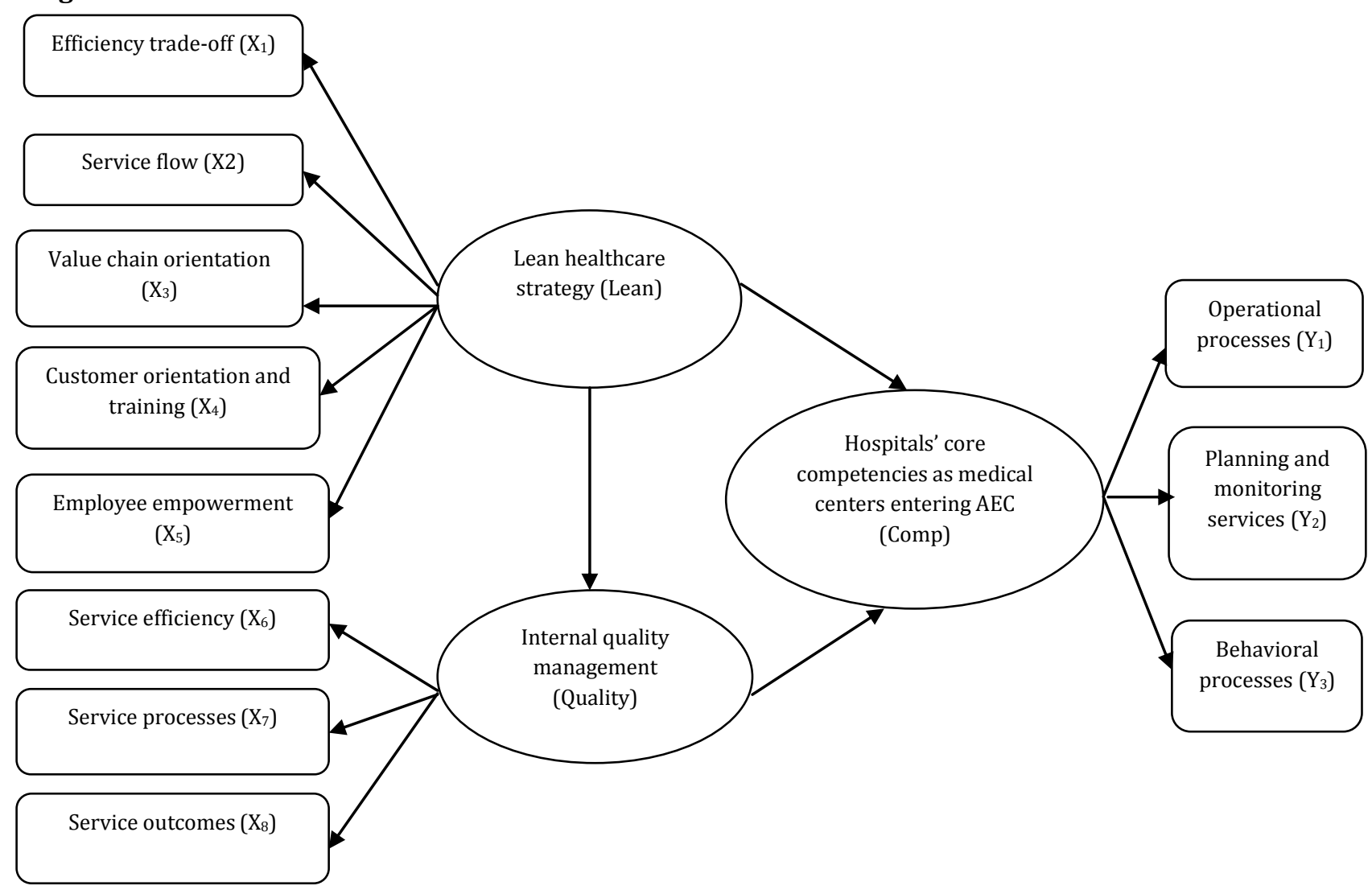

Research hypothesis: As per figure 1; Bowen \& Youngdahl, (1998) mentioned that Lean healthcare is comprised of Efficiency trade-off, Service flow, Value chain orientation, Customer orientation and training, and Employee empowerment. In addition, Ponanake et al. (2014) found that the lean healthcare system indirectly influences, through internal quality management, a hospital's core competency to be an AEC medical care center. Therefore, the following hypothesis is proposed: 
$\boldsymbol{H}_{1}$ : The Lean healthcare strategy indirectly influences hospitals' core competencies as medical centers entering the AEC through internal quality management.

Radnor (2010) which pointed that Lean can be applied to the central administration and local administration of the healthcare industry. Besides Ponanake (2014) found that the opinions level of Lean management system in healthcare business had influenced on core competency of Thai private hospitals' organization to be the medical care centre in ASEAN Economic Community had the significant at 0.01 . Therefore, the following hypothesis is proposed:

$\boldsymbol{H}_{2}$ : The Lean healthcare strategy directly influences hospitals' core competencies as medical centers entering the AEC.

Ponanake et al. (2014) found that The quality management which had influenced on core competency of Thai private hospitals' organization to be the medical care centre in ASEAN Economic Community had significant at 0.01., Ponanake et al. (2014) mentioned that internal quality management directly influences a hospital's core competency to be an AEC medical care center. Moreover, Kersten \& Koch (2010) studied the impact of quality management on the service quality and successful logistics of service providers. Their research found that Service efficiency and Service processes had positive impacts on successful businesses. Thus, the following hypothesis is proposed:

$\boldsymbol{H}_{3}$ : Internal quality management indirectly influences hospitals' core competencies as medical centers entering the AEC.

Statistical Data Analysis: To calculate inferential statistics to study hospitals' core competencies with Lean healthcare strategies in the AEC, the data were analyzed using Structural Equation Modeling (SEM). The goodness of fit of the model was tested with Chi-squares $\left(x^{2}\right), G F I, C F I, R M S E A$ (Hair et al., 2010) as follows:

\begin{tabular}{ll}
\hline Statistic & Criteria \\
\hline Chi-square $\left(x^{2}\right)$ & p-value $>0.05$ \\
Root Mean Square Error of Approximation (RMSEA) & $<0.05$ \\
Goodness of Fit Index (GFI) & $\geq 0.90$ \\
Comparative Fit Index (CFI) & $\geq 0.90$ \\
\hline
\end{tabular}

\section{Results}

The total population of HAs in private hospitals in Thailand was 384 persons. The analysis found that of hospitals in which HAs worked, 45.80 percent had 151-300 beds, 41.10 percent were located in Bangkok, 96.60 percent gave specialized treatment, 51.80 percent employed foreign officers or staff to serve foreign patients, 40.60 percent had applied the Lean system and Six Sigma in quality management for more than 5 years, 21.40 percent were certified by HAs, 33.30 percent were managed for reasons of organizational policy and the safety of patients, operators and the community.

\section{Figure 2: Hypothesis Model of the Structural Equation Modeling Analysis: SEM}

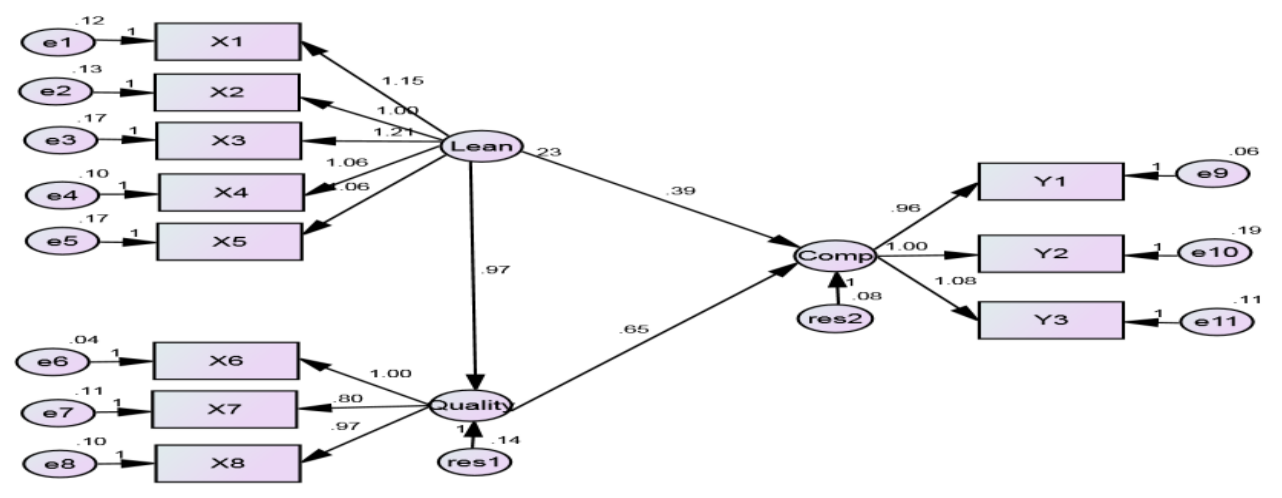


Figure 2 shows the examination of the relationship between exogenous variables and endogenous variables in accordance with the hypotheses and data from the sample with the $x^{2}-t e s t$, which found that the p-value was less than 0.05 ( $p$-value $=0.000$ ), indicating that the model hypothesis did not correspond with the data from the sample. Therefore, the adjusted model of the analysis is shown in Figures 3.

Figure 3: The result of adjusted model of the Structural Equation Modeling Analysis

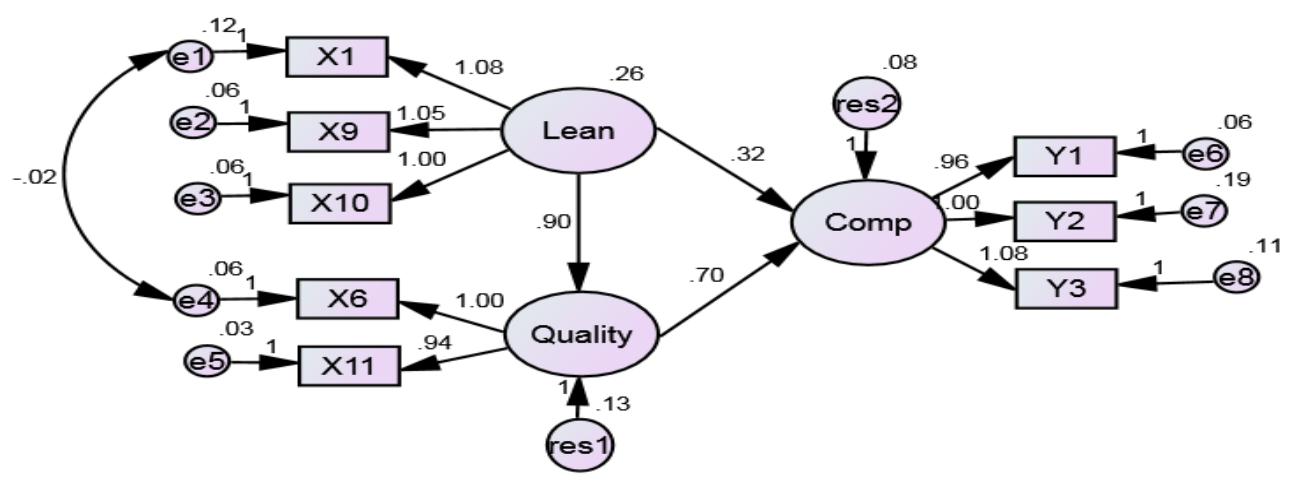

From Figures 3; $X_{2}$ and $X_{3}$ variables were computed into the $X_{9}$ variable, and $X_{4}, X_{5}$ variables were computed into the $\mathrm{X}_{10}$ variable. In addition, $\mathrm{X}_{7}$ and $\mathrm{X}_{8}$ variables were computed into the $\mathrm{X}_{11}$ variable. Table 2 shows the results of the model fit testing.

Table 2: Results of the model fit testing

\begin{tabular}{|c|c|c|}
\hline Test Statistics & Statistical Value & p-value \\
\hline$x^{2}$ & 19.659 & .236 \\
\hline GFI & .987 & - \\
\hline CFI & .999 & - \\
\hline RMSEA & .024 & - \\
\hline
\end{tabular}

Table 2 shows the adjusted model fit testing between exogenous variables and endogenous variables in accordance with the research report of the sample data, which found that the p-value of $\left(x^{2}\right)$ was more than 0.05 (p-value $=0.236$ ), indicating that the model of hypothesis corresponds with the sample data. The RMSEA was 0.024 less than $0.05, \mathrm{GFI}=0.987$ and $\mathrm{CFI}=0.999$, indicating that this model fit the data. Figure 3 shows the calculation of the direct, indirect and total influence of the Lean and quality variables on comp variables as shown in Table 4 and with the abbreviations of these variables ; Unstandardized Path Coefficient and $\mathrm{R}^{2}$ of Structural Equitation Model as shown in Table 3.

Table 3: The abbreviations of variables in the adjusted model; Unstandardized Path Coefficient and $\mathbf{R}^{2}$ of Structural Equitation Model

\begin{tabular}{|c|c|c|c|c|}
\hline Latent Variable & Observed Variable & $\begin{array}{l}\text { Unstandardized } \\
\text { Coefficient }\end{array}$ & Path & $\mathbf{R}^{2}$ \\
\hline $\begin{array}{lll}\text { Lean } & \text { Healthcare } & \text { Strategy }\end{array}$ & Efficiency Trade-off $\left(\mathrm{X}_{1}\right)$ & 1.08 & & .71 \\
\hline \multirow{2}{*}{ (Lean) } & Service efficiency $\left(\mathrm{X}_{6}\right)$ & 1.05 & & .86 \\
\hline & $\begin{array}{l}\text { Supply chain orientation and service } \\
\text { flow }\left(\mathrm{X}_{9}\right)\end{array}$ & 1.00 & & .82 \\
\hline Internal & Customer orientation $\left(\mathrm{X}_{10}\right)$ & 1.00 & & .81 \\
\hline Management (Quality) & Operation services $\left(\mathrm{X}_{11}\right)$ & 0.94 & & .92 \\
\hline Hospitals' core competencies & Operational processes $\left(\mathrm{Y}_{1}\right)$ & 0.96 & & .86 \\
\hline as medical centers entering & Planning and monitoring services $\left(\mathrm{Y}_{2}\right)$ & 1.00 & & .66 \\
\hline AEC (Comp) & Behavioral Services $\left(\mathrm{Y}_{3}\right)$ & 1.08 & & .79 \\
\hline
\end{tabular}


Table 4: Direct influence, indirect influence and total influence of Lean and Quality on Comp

\begin{tabular}{llllllllll}
\hline & Lean & \multicolumn{3}{c}{ Quality } & \multicolumn{7}{c}{ Comp } \\
Influence & DE & IE & TE & DE & IE & TE & DE & IE & TE \\
\hline Lean & - & - & - & 0.90 & - & 0.90 & 0.32 & 0.63 & 0.95 \\
& & & & $\left(0.00^{* *}\right)$ & & $\left(0.00^{* *}\right)$ & $\left(0.00^{* *}\right)$ & $\left(0.00^{* *}\right)$ & $\left(0.00^{* *}\right)$ \\
Quality & - & - & - & - & - & - & 0.70 & - & 0.70 \\
& & & & & & & $\left(0.00^{* *}\right)$ & $\left(0.00^{* *}\right)$ \\
\hline
\end{tabular}

Note: DE = Direct Effect

$\mathrm{IE}=$ Indirect Effect

$\mathrm{TE}=$ Total Effect

$* *=$ Statistical significant at .01

The number in ( ) is p-value

Table 4 shows that the Lean healthcare strategy (Lean) directly influenced hospitals' core competencies in entering the AEC (Comp) $=0.32$ at the 0.01 significance level. Internal quality management (Quality) directly influenced hospitals' core competencies in entering the AEC (Comp) $=0.70$ at the 0.01 significance level. The Lean healthcare strategy (Lean) directly influenced internal quality management (Quality) $=0.90$ at the 0.01 significance level. The Lean healthcare strategy (Lean) indirectly influenced hospitals' core competencies in entering the AEC $(\mathrm{Comp})=0.63$ through internal quality management at the 0.01 significance level. The Lean healthcare strategy (Lean) had a total influence on hospitals' core competencies in entering the AEC (Comp) = 0.95 at the 0.01 significance level. Internal quality management had a total influence on hospitals' core competencies in entering the AEC (Comp) $=0.70$ at the 0.01 significance level. The Lean healthcare strategy (Lean) had a total influence on internal quality management (Quality) $=0.90$ at the 0.01 significance level.

\section{Table 5: Summary of Hypothesis Testing Results}

\begin{tabular}{|c|c|}
\hline \multirow[t]{2}{*}{ Hypothesis } & Hypothesis Testing Results \\
\hline & Accepted $\quad$ Rejected \\
\hline $\begin{array}{l}\mathbf{H}_{1} \text { : The Lean healthcare strategy indirectly influences hospitals' } \\
\text { core competencies as medical centers entering the AEC through } \\
\text { internal quality management. }\end{array}$ & $\checkmark$ \\
\hline $\begin{array}{l}\mathbf{H}_{2} \text { : The Lean healthcare strategy directly influences hospitals' } \\
\text { core competencies as medical centers entering the AEC. }\end{array}$ & $\checkmark$ \\
\hline $\begin{array}{l}\mathbf{H}_{3} \text { : Internal quality management indirectly influences hospitals' } \\
\text { core competencies as medical centers entering the AEC. }\end{array}$ & $\checkmark$ \\
\hline
\end{tabular}

Discussion: Hypothesis testing found that the Lean Healthcare strategy (Lean) directly influences hospitals' core competencies in entering the AEC (Comp). This corresponds to the research on Core Competency of Thai Private Hospitals' Organization to be the Medical Care Centre in ASEAN Economic Community (AEC) (Ponanake, 2014). The studied fond that Lean management system in healthcare business which had influenced on core competency of Thai private hospitals' organization to be the medical care centre in ASEAN Economic Community had the significant at 0.05 and correspond to Verma \& Boyer (2008) which pointed that under Lean framework, all activities had to carefully be evaluated with respect to quality to ensure that customers actually received value from the activities and that unvalued added activities should be eliminated. As per the Lean healthcare concept, the patient is the most important customer, so a hospital should meet customers' needs by maintaining quality standards so that patients can access services easily and conveniently (Dickson et al., 2009). The Lean Healthcare strategy (Lean) directly influences internal quality management (Quality). This correspond to Radnor (2010) which pointed that Lean can be applied to the central administration and local administration of the healthcare industry. To apply Lean in the healthcare industry, hospitals should reduce duplicate processes and unnecessary steps, such as keeping patients' data in many places, long waiting times and unnecessary waiting times (Radnor et al., 2012).

Internal quality management (Quality) directly influences hospitals' core competencies in entering the AEC (Comp). The Lean Healthcare strategy (Lean) indirectly influences hospitals' core competencies in entering the AEC (Comp) through internal quality management. This corresponds to the research on Path Analysis of 
the Core Competency of Thai Private Hospitals in the ASEAN Economic Community (Ponanake et al., 2014). The study determined that internal quality management directly influences a hospital's core competency to be an AEC medical care center and the lean healthcare system indirectly influences, through internal quality management, a hospital's core competency to be an AEC medical care center. So the private Thai hospitals should concentrate on time and timeliness which determined that how long the patient wait for service (Russell \& Talor III, 2011) and should to eliminate the waste from patient's waiting time and improve the patient flow. The Lean Healthcare strategy (Lean) had a total influence on hospitals' core competencies in entering the AEC (Comp). Internal quality management had a total influence on hospitals' core competencies in entering the AEC (Comp). Thus, private Thai hospitals should establish customer satisfaction from initial contact until patients leave the hospital. To create hospitals' core competencies in entering the AEC, the Lean strategy should help to evaluate waste in processes by value stream mapping, which would eliminate the nonvalue added of patients and help the process flow (Dickson et al., 2009).

\section{Conclusion and Recommendations}

Based on the data collected from the sample group, it was determined that the lean system in healthcare business was applied in hospital groups through internal quality management to establish core competency of Thai private hospitals in competition. Lean's benefits include that it reduces costs in hospitals by eliminating the non-value added activities to meet customer satisfaction. A popular tool used by the lean system to assess the non-value added activity is the value steam mapping (VSM) (Fitzsimmons et al., 2013) as presented in the brown paper analysis method which will show the Muda (waste) in each activity. It would be advantageous when establishing the core competency of Thai private hospitals entering AEC competition to eliminate the waiting time of patients and to improve patient flow control. This study suggests that the owners of private Thai hospitals should set line service balancing by add more physicians during time which has many patients. In addition the owners of private Thai hospitals should encourage their staff to learn other languages, such as Chinese, Bahasa Indonesia, Lao, German, French and Russian, to accommodate foreign customers and the AEC, which would be advantageous in terms of competition and would also respond to customer demand according to the Lean system. Furthermore, owners should encourage service mindsets in their staff, which strengthen the core competencies of Thai private hospitals entering the AEC and produce competitive advantages according to the Lean Healthcare strategy. The results suggest that future research should study the relationship between Lean Sixma and internal quality management within organizations to build the core competencies of hospitals entering the AEC.

\section{References}

Brandao-de Souza, L. (2009). Trends and approaches in lean healthcare. Leadership in Health Services, 22(2), 121-139.

Bowen, D. E. \& Youngdahl, W. E. (1998). Lean service: in defense of a production-line approach. International Journal of Service Industry Management, 9(3), 207-225.

Dean, H. W. \& Bowen, D. E. (1994). Management theory and total quality: improving research and practice through theory development. The Academy of Management Review, 19(3), 392-418.

Enderwick, P. \& Nagar, S. (2011). The competitive challenge of emerging markets: the case of medical tourism. International Journal of Emerging Markets, 6(4), 329-350.

Dickson, E. W., Singh, S., Cheung, D. S., Wyatt, C. C. \& Nugent, A. S. (2009). Application of Lean Manufacturing Techniques in the Emergency Department. The Journal of Emergency Medicine, 37(2), 177-182.

Daft, R. L. (2010). Understanding The Theory and Design of Organizations (10th ed.), China: China Translation \& Printing Services limited.

Fitzsimmons, J. A., Fitzsimmons, M. J. \& Bordoloi, S. K. (2013). Service Management (8th ed.), Singapore: McGraw-Hill Irwin.

Grout, J. R. \& Toussaint, J. S. (2010). Mistake-proofing healthcare: Why stopping processes may be a good start. Business Horizons, 53, 149-156.

Hair, J., Black, W., Babin, B. \& Anderson, R. (2010). Multivariate Data Analysis: A global perspective. $7^{\text {th }}$ published. New Jersey: Pearson Education.

Holweg, M. (2007). The genealogy of lean production. Journal of Operations Management, 25, 420-437. 
Kersten, W. \& Koch, J. (2010). The effect of quality management on the service quality and business success of logistics service providers. International Journal of Quality \& Reliability Management, 27(2), 185 200.

Ponanake, P. (2014). Core Competency of Thai Private Hospitals' Organization to be the Medical Care Centre in ASEAN Economic Community (AEC). International Journal of Multidisciplinary Thought, 3(2), 339346.

Ponanake, P., Limnararat, S., Pithuncharurnlap, M. \& Sangmanee, W. (2014). Path Analysis of Core Competency of Thai Private Hospitals in AEC. Research Journal of Business Management, 8(3), 157172.

Ponanake, P., Limnararat, S., Pithuncharurnlap, M. \& Sangmanee, W. (2014). Influence of Internal Quality Management on Core Competency of Thai Private Hospitals to be the Medical Care Center in ASEAN Economic Community. International Journal of Multidisciplinary Thought, 4(1), 259-265.

Prajogo, D. I. \& McDermott, D. M. (2005). The relationship between total quality management practices and organizational culture. International Journal of Operations \& Production Management, 25(11), 110122.

Radnor, Z. J. (2010). Review of business process improvement methodologies in public services. Advanced Institute of Management.

Radnor, Z. J., Holweg, M. \& Waring, J. (2012). Lean in healthcare: The unfilled promise? Social Science \& Medicine, 74, 364-371.

Rao, P. \& Holt, D. (2005). Do green supply chains lead to competitiveness and economic performance? International Journal of Operations and Production Management, 25(9), 898-916.

Robinson, S., Radnor, Z. J., Burgess, N. \& Worthington, C. (2012). SimLean: Utilizing simulation in the implementation of lean in healthcare. European Journal of Operational Research, 219, 188-197.

Russell, R. S. \& Talor III, B. W. (2011). Operation Management (7th ed.), NJ: John Wiley \& Sons (Asia).

Shuai, J. J., Su, Y. F. \& Yang, C. (2007). The Impact of ERP Implementation on Corporate Supply Chain Performance. Proceedings of the 2007 IEEE IEEM.

Sousa, R. \& Voss, C. A. (2002). Quality management re-visited: a reflective review and agenda for future research. Journal of Operations Management, 20, 91-109.

Verma, R. \& Boyer, K. (2008). Operations and supply chain management. China: China Translation \& Printing Services Limited.

Womack, J. P. \& Jones, D. T. (1996). Beyond Toyota: how to root out waste and pursue perfection. Harvard Business Review, 74(5), 140-158.

Zu X., Fredendall, L. D. \& Douglas, T. J. (2008). The evolving theory of quality management: The role of Six Sigma. Journal of Operations Management, 26, 630-650. 